\title{
Histological, Histochemical and UItrastructural Changes in the Submandibular Gland of Starved Young Male Cats
}

\section{EL-Kordy EA ${ }^{1 *}$, Alanazi $\mathrm{AD}^{2}$, Ali SS ${ }^{3}$, Makhlouf $\mathrm{MMM}^{4}$ and Rabah $\mathrm{SO}^{5}$}

${ }^{1}$ Department of Histology, Faculty of Medicine, Tanta university, Egypt- Shaqra University, Saudi Arabia

${ }^{2}$ Department of Biological Sciences, Faculty of Science and Humanities, Shaqra University, Saudi Arabia

${ }^{3}$ Department of Anatomy, Faculty of medicine, King Abdul Aziz university, Saudi Arabia

${ }^{4}$ Department of Laboratories, Faculty of applied medical sciences Shaqra University, Saudi Arabia

${ }^{5}$ Department of Biology, Faculty of Science, King Abdul Aziz university, Saudi Arabia

\begin{abstract}
Introduction: The submandibular gland is the largest salivary glands that secrete saliva. Starvation or food deprivation was found to influence all body metabolic activities that are reflected on the structure of many organs including salivary glands.
\end{abstract}

Aim of the work: This work is aimed to study the possible histological, histochemical and ultrastructural changes of submandibular gland associated with long-term ( 7 and 14 days) food deprivation.

Materials and Methods: Twenty young male cats were divided into 2 main groups. Group I: served as control received solid diet for 7 and 14 days. Group II: animals were starved for 7 and 14 days. The cats were sacrificed and specimens from submandibular gland were taken for light and electron microscopic examination.

Results: Light microscopic examination of starved cats revealed distension of secretory units with secretory granules, vacuolated cytoplasm and pyknotic nuclei. The changes were augmented with prolongation of periods of starvation for 14 days. Histochemically, starvation leads to a decrease or alteration in metachromatic staining of secretory granules that tends to be unstained with prolonged period of starvation for 14 days. Ultrastructurally, the secretory granules of acinar and demilunar cells appeared with more electron dense with degeneration of rough endoplasmic reticulum and mitochondria as well as significant accumulation of lipid droplets within these cells and in striated ducts.

Conclusion: Results obtained in this study demonstrated that food deprivation for long periods induced marked histological, histochemical and ultrastructural changes in the submandibular gland as well as altered saliva composition with a concomitant decrease in acid and neutral mucosubstances.

Keywords: Starvation; Submandibular salivary gland; Saliva

\section{Introduction}

The salivary glands play important role in the digestive system that develop at different sites and produce different types of saliva. The main salivary glands are 3 pairs: parotid, submandibular and sublingual glands [1-3]. The submandibular gland is the largest salivary gland; it shows peculiar structure in different animal species $[4,5]$.

These glands secrete saliva which is a complex fluid containing various enzymes, water, mucopolysaccharides and lubricating glycoprotein [6]. The saliva have many functions, moisten the mucous membrane of the upper digestive tract, facilitate the speech, control the bacteria flora of the mouth, produce antimicrobial substances, maintain tooth integrity and prepare food for digestion $[7,8]$.

The total volume of saliva produced each day in adults is 500 to 1500 ml. Mixed saliva, consists mainly of the secretions of submandibular (65\%), parotid (23\%), sublingual (4\%) glands and the remaining $8 \%$ being provided by the minor numerous glands [9]. The salivary flow is related to the functions of salivary glands. Therefore, any alteration of the integrity and activity of salivary glands can change saliva flow and composition $[10,11]$.

Awareness of the importance of the salivary glands to health and sense of well-being of the individual is increasingly evident. It is also a fact that its structure and functions show diverse variations depending on animal species as well as upon food intake and consistency [12].

Starvation or food deprivation was found to influence all body metabolic activities that are reflected on the structure of many organs including colon, liver, brain and pituitary gland [13-15].

As far as we know, there are limited studies in the literature conducted in humans. The effects of nutrition and diet should be assessed in terms of flow secretion and saliva composition. Nevertheless, the findings in humans are markedly similar to the results of animal studies. Therefore, knowledge from the animal model is helpful for the understanding of the cellular gland alterations, as well as their influence on saliva composition [16].

Based on these, this study was aimed to study the effect of long-term (7 and 14 days) food deprivation on the male cat submandibular gland. This study included histological, histochemical and ultrastructural investigations.

*Corresponding author: Eman A. EL-Kordy, Department of Histology, Faculty of Medicine, Tanta university, Egypt- Shaqra University, Saudi Arabia, Tel: 00966508958883; E-mail: emanalimah@yahoo.com; emanali@su.edu.sa

Received April 11, 2014; Accepted June 05, 2014; Published June 07, 2014

Citation: EL-Kordy EA, Alanazi AD, Ali SS, Makhlouf MMM, Rabah SO (2014) Histological, Histochemical and Ultrastructural Changes in the Submandibular Gland of Starved Young Male Cats. J Cytol Histol 5: 252. doi:10.4172/21577099.1000252

Copyright: () 2014 EL-Kordy EA, et al. This is an open-access article distributed under the terms of the Creative Commons Attribution License, which permits unrestricted use, distribution, and reproduction in any medium, provided the original author and source are credited. 
Citation: EL-Kordy EA, Alanazi AD, Ali SS, Makhlouf MMM, Rabah SO (2014) Histological, Histochemical and Ultrastructural Changes in the Submandibular Gland of Starved Young Male Cats. J Cytol Histol 5: 252. doi:10.4172/2157-7099.1000252

\section{Materials and Methods}

\section{Animals}

Healthy twenty young male cats aged 2 months weighing 1.0-1.5 $\mathrm{kg}$ were used in this study. The animals were housed in clean properly ventilated cages in the animal house in the faculty of Medicine, Assiut University. They were kept under normal conditions and had free access to water. Ethical approval was obtained from the ethical committee of Assiut Faculty of Medicine. Cats were randomly divided into 2 main groups:

Group I (control group): 6 animals were fed the basal diet for 7 and 14 days and were divided into 2 subgroups, 3 animals each as follow:

Subgroup Ia: received free solid diet for 7 days.

Subgroup Ib: received free solid diet for 14 days.

Group II (starved group):14 animals were starved for 7 and 14 days. They were divided into 2 subgroups, 7 animals each as follow:

Subgroup IIa: animals were starved for 7 days.

Subgroup IIb: animals were starved for 14 days.

After 7 and 14 days, control and starved cats were sacrificed by ether anesthesia, specimens from the submandibular gland were taken, put in $10 \%$ buffered formalin for fixation, processed for examination by light microscopy. 4-6 micrometer sections were obtained and stained with haematoxylin and eosin ( $\mathrm{H} \& \mathrm{E})$ to verify histological details and histochemical staining, Alcian blue-PAS reactions for detection of mucoplysaccharides. By this method acid mucopolysaccharides are stained blue, neutral mucoplysaccharides appear red, and the mixture of both stains purple [17].

For electron microscopy, small pieces from the submandibular gland were fixed in 5\% cold gluteraldehye for at least 24 hours then washed in 3-4 changes of cacodylate buffer ( $\mathrm{pH} 7.2$ ) for 20 minutes in each change and post fixed in cold osmium tetroxide for 2 hours. The specimens were washed in four changes of cacodylate buffer for 20 minutes for each. Dehydration was done by using ascending grades of alcohol $(30,50,70 \%)$ each for 2 hours and then $90 \%, 100 \%$ two changes 30 minute each. Embedding was done in Epon 812 using gelatin capsules for polymerization. The embedded samples were kept in incubator at $35^{\circ} \mathrm{C}$ for one day, at $45^{\circ} \mathrm{C}$ for another day and for three days at $60^{\circ} \mathrm{C}$. Then semithin sections (0.5-1 microns) were prepared by using LKB ultramicrotome. The sections were stained with toluidine blue, examined with light microscope and photographed. Ultrathin sections (50-80 nm) from selected areas of the trimmed blocks were made and collected on copper grides. The ultrathin sections were contrasted with uranyl acetate for 10 minutes, lead citrate for 5 minutes [18]. Finally, the sections were examined and photographed by transmission electron microscopy (Jeol JEM- 100CX II EM) in Assiut University Electron Microscopy Unit.

\section{Results}

\section{Control group (group I)}

Examination of $\mathrm{H} \& \mathrm{E}$ stained sections of cat submanibular salivary gland of control group was found to be made of mucous and serous secretary end pieces oftenly capped with seromucous demilunes as well as a duct system which is formed of intercalated, striated and excretory ducts. The myoepithelial cells are present between the base of the acinar cells and the basal lamina (Figure 1). Using semithin sections stained with toluidine blue, the acinar cells secretory granules showed varying degrees of metachromasia (deep purple to pink). Most of the demilunar cell granules are stained faint pink with this stain. The intercalated and striated ducts appeared unstained (Figures 2 and 3).

Regarding the histochemistry, using Alcian blue-PAS reactions, there is a marked variation in the distribution and intensity of both PAS and Alcian blue positive materials in different regions of the gland and even in the same lobule or the secretory units. Generally most of acinar cells contain mixture of both neutral and acid polysaccharides as they are stained deep purple with this technique. Demilunar cells most probably contain a considerable amount of sulphated mucopolysaccharides as they are stained blue by Alcian blue- PAS technique .The duct system showed negative reactions except of faint PAS positive material in the nuclei of lining cells and faint Alcian blue positive material along the luminal surface of the lining cells (Figures 4 and 5).

Ultrastructurally, the mucous acini appeared with narrow lumen bordered by large pyramidal cells have vesicular nuclei with all the cell

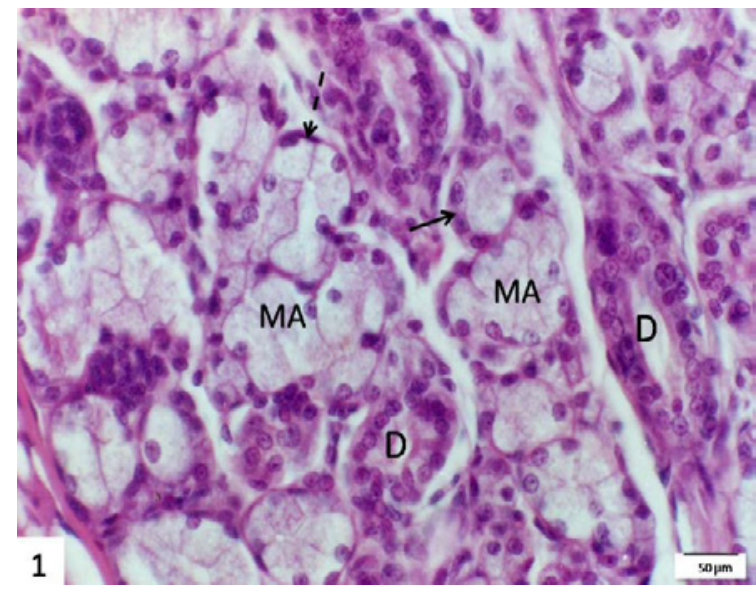

Figure 1: A section in the submandibular gland of the control group stained with H\&E showing mucous acini (MA) with cuboidal shaped cells and pale basophilic vacuolated cytoplasm as well as the serous demilunes (arrow). Note, the striated ducts (D) and the myoepithelial cells (dotted arrow) gasping the acini. Scale bar $=50 \mu \mathrm{m}$.

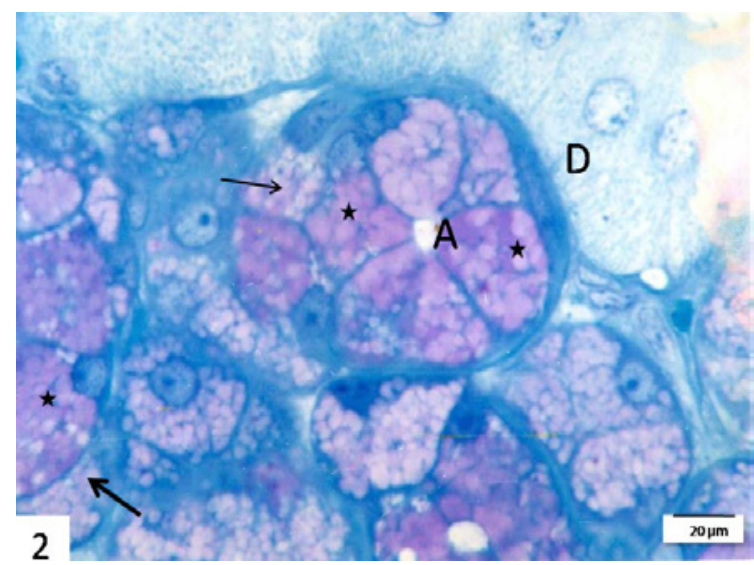

Figure 2: A semithin section in the submandibular gland of the control group stained with toluidine blue showing metachromatic secretory granules (stars) of varying staining intensity in the acinar cells $(A)$. The cells of serous demilunes are faintly metachomatic (thin arrow) or unstained (thick arrow). The striated duct cells (D) are also unstained. Scale bar=20 $\mu \mathrm{m}$. 
Citation: EL-Kordy EA, Alanazi AD, Ali SS, Makhlouf MMM, Rabah SO (2014) Histological, Histochemical and Ultrastructural Changes in the Submandibular Gland of Starved Young Male Cats. J Cytol Histol 5: 252. doi:10.4172/2157-7099.1000252

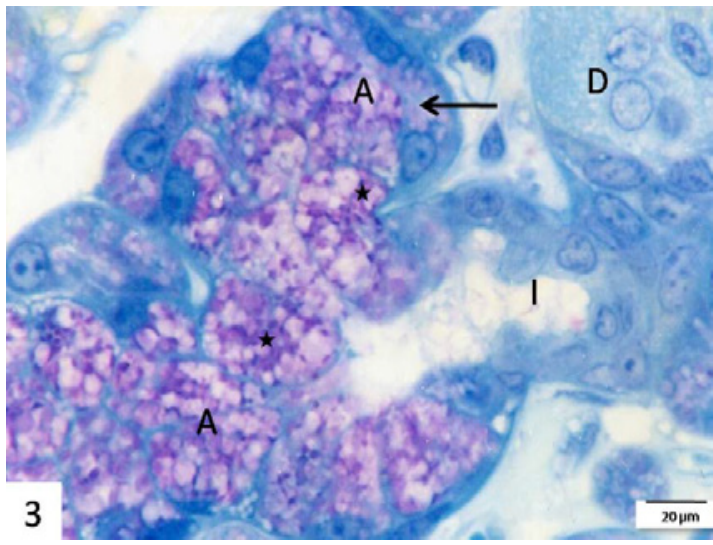

Figure 3: A semithin section in the submandibular gland of the control group stained with toluidine blue showing distention of acinar cells $(A)$ with metachromatic secretory granules (stars). Note, faint metachomatic staining of serous demilunes (arrow) and the unstained intercalated (I) and the striated ducts (D). Scale bar=20 $\mu \mathrm{m}$

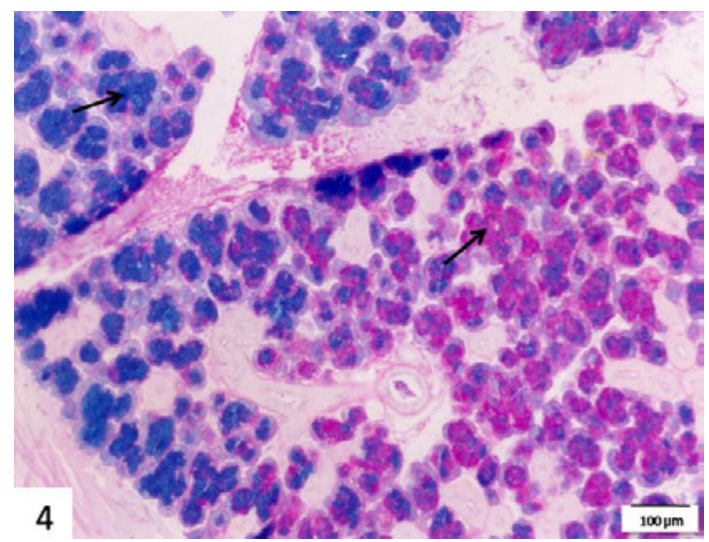

Figure 4: A section in the submandibular gland of the control group stained with Alcian blue-PAS stain showing marked variation in the distribution and intensity of both PAS and Alcian blue positive material (arrows) in different regions of the gland and even in the same lobule or secretory units. Scale bar $=100 \mu \mathrm{m}$.

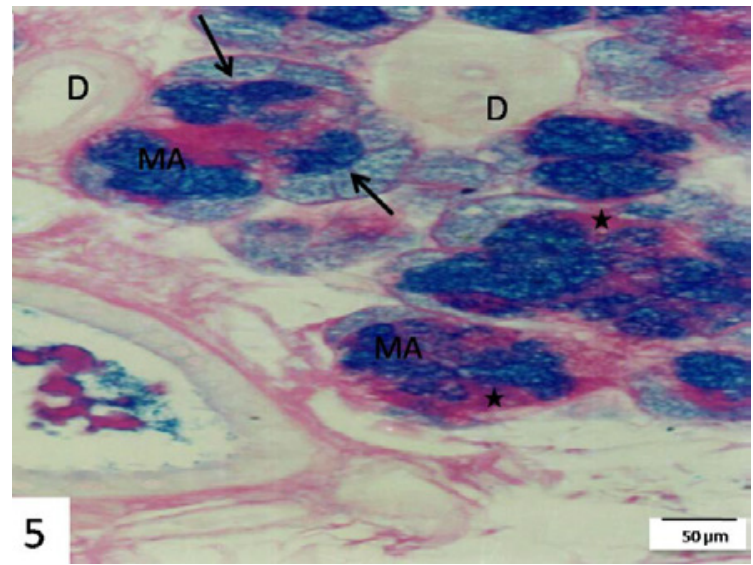

Figure 5: A magnified part of the previous section showing most of mucous acini stained deep purple (MA) and acid mucosubstances stained blue in the demilune cells (arrows). Note, The duct cells (D) showed -ve reaction and neutral mucosubstances stained red in some mucous acinar cells (stars). Scale bar $=50 \mu \mathrm{m}$. organoids of secretory cells, numerous rough endoplasmic reticulum (rER), randomly distributed mitochondria and Golgi bodies The apical parts of the cytoplasm are packaged with numerous secretory granules, some of them are electron lucent and others contain moderately electron dense material. The demilune cells possess large oval nuclei with prominent nucleoli. The cytoplasm contains extensive rER, Golgi bodies, mitochondria and electron lucent secretory granules (Figure 6). The ultrastructural studies of the striated ducts revealed that, the light cells are the dominating types of cells with large, rounded abundant euchromatic nuclei. Their basal cell membrane exhibits complex extensive infoldings enclose numerous mitochondria with tubular cristae. The supranuclear region contains ill-defined electron lucent granules, moderately electron dense granules (Figure 7).

\section{Starved group for 7 days (subgroup IIa)}

Starvation for 7 days led to obvious histological changes in the structure of submandibular gland. Sections stained by $\mathrm{H} \& \mathrm{E}$ showed slight hypertophied of the acini and distended prominent demilunar cells. The normal architecture of acinar cells was distorted; their nuclei

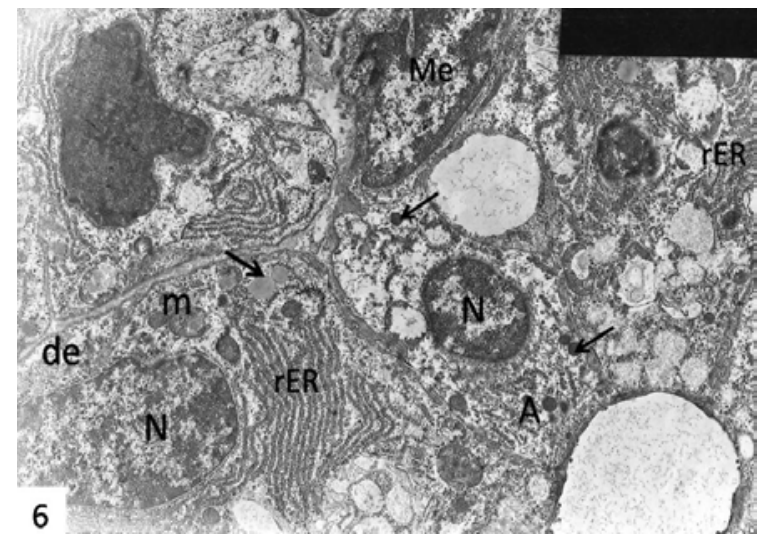

Figure 6: An electron micrograph of control submandibular gland showing normal shaped acinar cells (A) grouped around lumens and demilunar cells (de). The cells showing vesicular nucleus $(\mathrm{N}$ ), all the cell organoids of secretory cells, ,well developed rough endoplasmic reticulum ( $r E R)$, numerous mitochondria (m), electron dense (thin arrows) and electron lucent (thick arrow) granules. Note, a myoepithelial cell (Me) surrounding the acinus. X 4000.

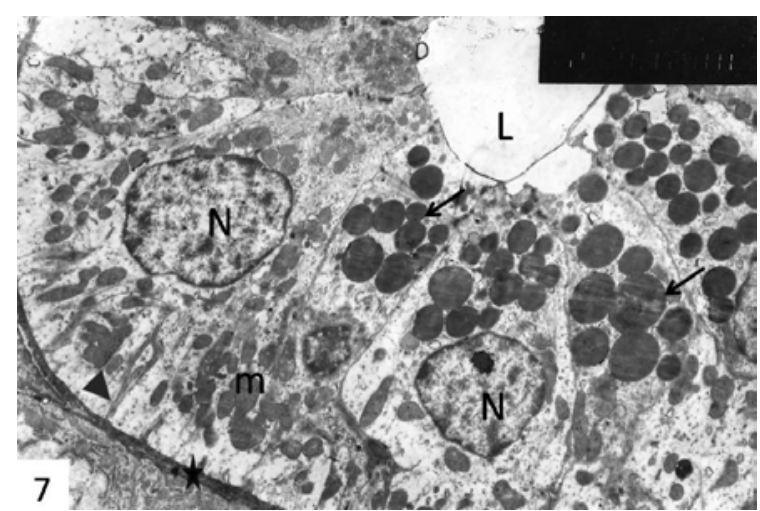

Figure 7: An electron micrograph of control submandibular gland showing normal shaped striated duct cells grouped around (L). The cells contain rounded central vesicular nuclei $(\mathrm{N})$ and numerous apical electron dense granules (arrows). Note, the intact basement membrane (star),basal membrane infoldings (arrow head) and the elongated mitochondria (m) arranged inbetween these infoldings. $X 4000$. 
Citation: EL-Kordy EA, Alanazi AD, Ali SS, Makhlouf MMM, Rabah SO (2014) Histological, Histochemical and Ultrastructural Changes in the Submandibular Gland of Starved Young Male Cats. J Cytol Histol 5: 252. doi:10.4172/2157-7099.1000252

became dark and deeply stained. The cytoplasm lost its basophilic character. Also, small and deeply stained nuclei of the demilunar cells were seen. The striated ducts appeared with more acidophilic cytoplasm (Figure 8). Examination of semithin sections stained with toluidine blue revealed a marked alteration in the staining characters of acinar secretory granules. Most of them lose their dark purple and pink coloration thus looking orthochromatic. The demilune cells appear distended with granules that show decrease in the intensity of pink coloration compared to the control. The striated ducts appeared unstained with disorganized lining cells and degenerated nuclei (Figures 9 and 10).

Histochemically, starvation for 7 days lead to variation in the distribution of both neutral and acid mucopolysaccharides in acinar and demilunar cells by using Alcian blue -PAS reaction. There was a decrease in both acid and neutral polysaccharides in acinar cells as they showed a decrease in the purple staining observed in control sections.

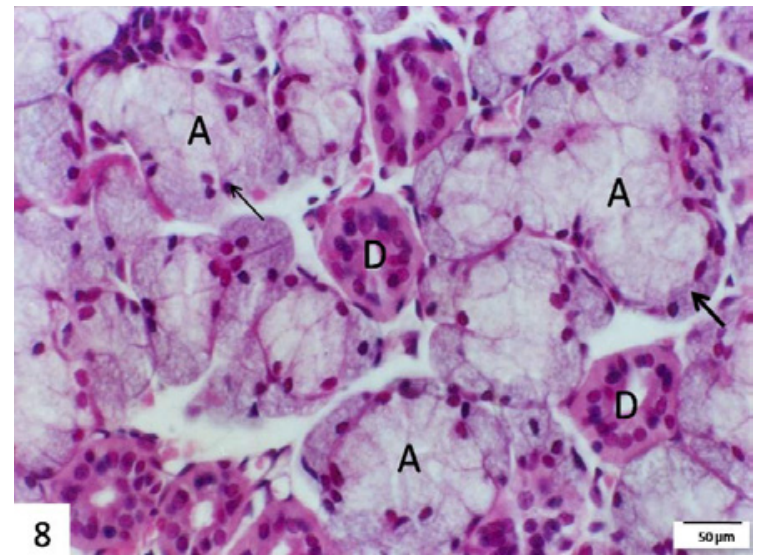

Figure 8: A section in the submandibular gland of 7 days starved group stained with H\&E showing slightly hypertrophied acini (A) with deeply stained nucle (thin arrow), prominent serous demilune (thick arrow) and striated ducts (D) with more acidophilic cytoplasm.) Scale bar $=50 \mu \mathrm{m}$ ).

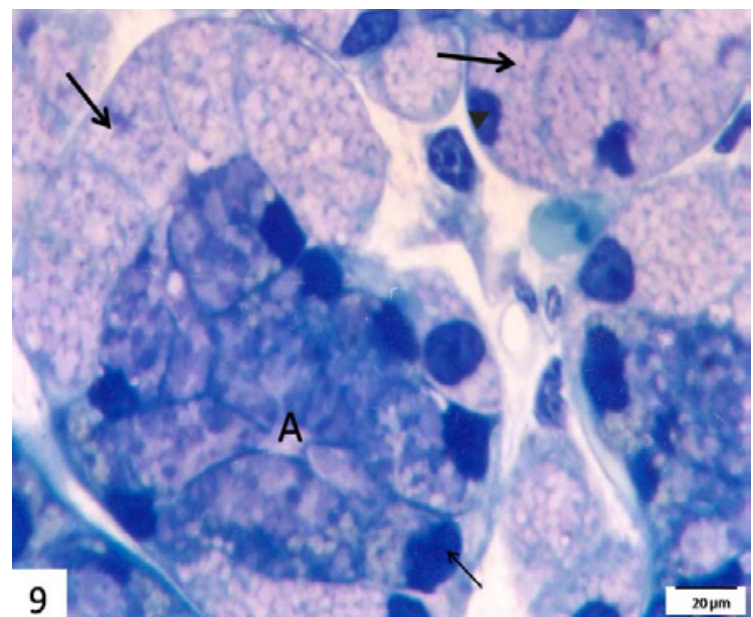

Figure 9: A semithin section in the submandibular gland of 7 days starved group stained with toluidine blue showing acinar cells (A) with loss of metachromatic staining of its content and irregular dark stained nuclei (thin arrow). Note, markedly distended demilune cells with faintly stained metachromatic granules (thick arrows) and their small dark stained (pyknotic) nuclei (arrow head). Scale bar $=20 \mu \mathrm{m}$.

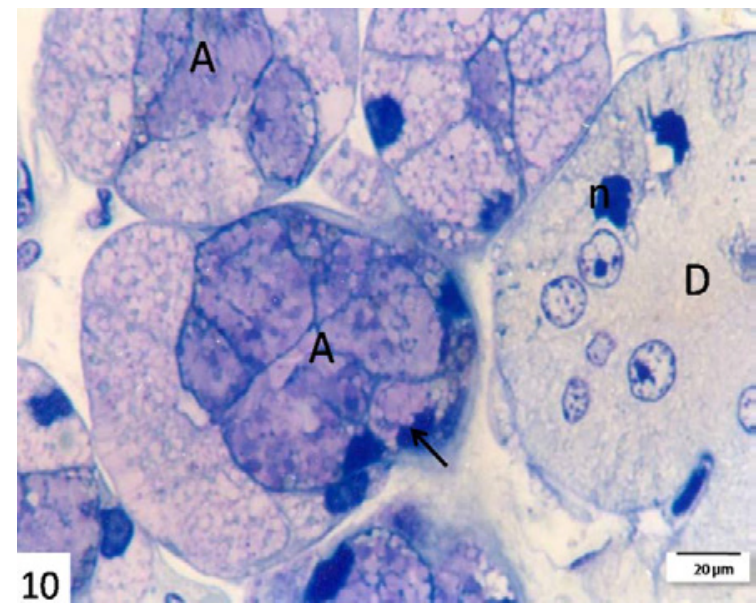

Figure 10: A semithin section in the submandibular gland of 7 days starved group stained with toluidine blue showing some acini with marked atrophy of the acinar components with loss of their metachromatic material $(A)$ and their small deeply stained nuclei (thin arrow). Note, unstained disorganized lining cells of a striated duct (D) and their degenerated nuclei (n). Scale bar=20 $\mu \mathrm{m}$.

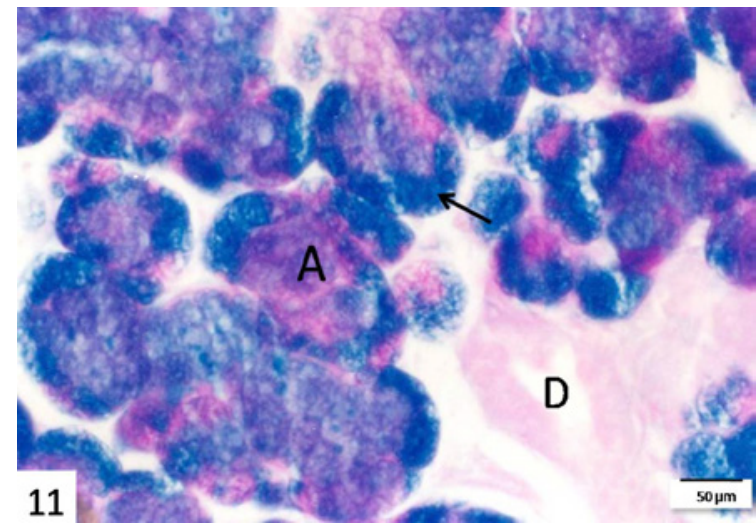

Figure 11: A section in the submandibular gland of 7 days starved group stained with Alcian blue-PAS stain showing a decrease of PAS positive material in the acinar part (A), while an increase in Alcian blue positive material in demilune cells (arrow). Note, no secretory material was stained in ductal cells (D). Scale bar $=50 \mu \mathrm{m}$

Also, PAS+ve acinar cells showed significant decrease in the amount of neutral mucoplysaccharides. There was an increase in the amount of acid mucopolysaccharides in the distended demilunar cells. No secretory material was stained in ductal cells (Figure 11).

Ultrastructural changes were observed in both acinar and demilune cells after starvation for 7 days. However, the changes in the latter are more evident. The mucous acinar cells showed marked accumulation of heterogenous secretory granules that mask other cellular organelles. The contents of the secretory granules are of varying electron densities and are finely granular. Some of the secretory granules fuse together to form large aggregates. The nucleus appeared deformed with electron dense nucleoplasm and heterocromatin clumps. The demilune cells showed irregular pyknotic nuclei with marked decrease in the rER which appear in the form of a few dilated strands containing electron dense material .The mitochondria were few in number and small lipid droplets were observed in the cytoplasm. The rest of the cytoplasm is filled with electron lucent secretory granules of varying sizes with 
Citation: EL-Kordy EA, Alanazi AD, Ali SS, Makhlouf MMM, Rabah SO (2014) Histological, Histochemical and Ultrastructural Changes in the Submandibular Gland of Starved Young Male Cats. J Cytol Histol 5: 252. doi:10.4172/2157-7099.1000252

destructed limiting membrane (Figure 12). The cells of the striated duct showed loss of its characteristic basal infoldings, disruption of mitochondria with fragmented cristae. A few scattered fine granules and vacuoles were also observed. The nuclei appeared small in size with condensed heterochromatin compared to those of the control one (Figure 13).

\section{Starved group for 14 days (subgroup IIb)}

Light microscopic examination of the submandibular gland of cats of this group showed augmentation of the changes by prolongation of the period of starvation. Marked distortion of secretory units with dilated lumens and small deeply stained nuclei were observed .The cytoplasm of the acinar cells appeared pale without distinct cellular features. Atrophied serous demilunes were seen (Figure 14). With prolonged starvation, there was complete loss of toluidine blue staining of acinar cells except of a few deeply stained blue granules near the luminal surface of the cells. Accumulation of lipid droplets in acinar

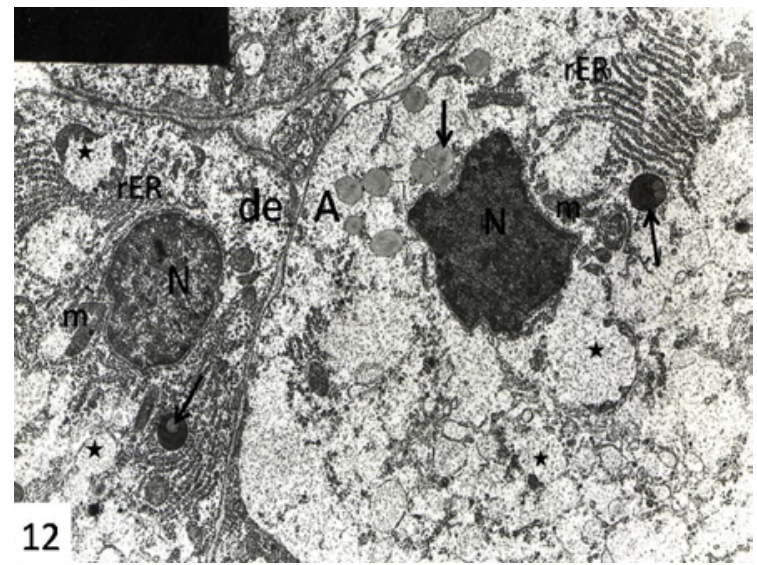

Figure 12: An electron micrograph of the submandibular gland of 7 days starved group showing marked cell organelles degeneration of acinar (A) and demilune (de) cells leaving few strands of rER, destructed mitochondria $(\mathrm{m})$, lipid droplets deposition (arrows) and deformed dense nuclei (N). Note secretory granules of varying sizes (stars). X 4000

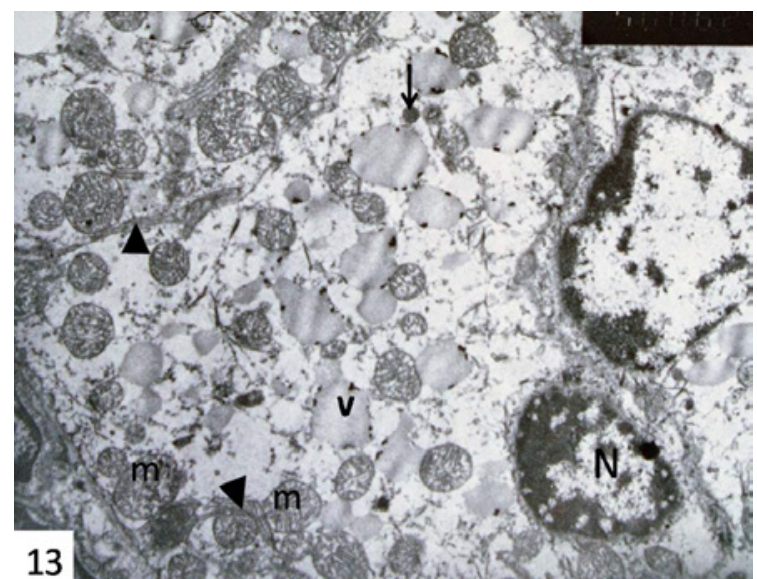

Figure 13: An electron micrograph of the submandibular gland of 7 days starved group showing the striated duct cells with small irregular condensed nucleus $(\mathrm{N})$, disrupted mitochondria $(\mathrm{m})$, a few scattered fine granules (arrow) and multiple vacuoles $(v)$. Note, the remnant of basal membrane infoldings (arrow heads). X 4000 cells of some units as well as in the cells of striated ducts was observed (Figure 15).

Regarding histochemistry, after 14 days of starvation, there was only few granular or fragmented residual of both neutral and acid mucopolysaccharides in acinar cells that showed a decrease in the intensity of staining reaction compared to the previous groups. Demilunar cells showed evident decrease in sulphated mucopolysaccharides contents. The duct cells showed slight increase in the intensity of both PAS and Alcian blue+ve substance compared to starved group for 7 days (Figure 16).

Ultrastructurally, starvation for 14 days leads to progressive changes in the structure of the submandibular gland. Degenerated acinar cells with complete loss of all cytoplasmic organelles and secretory granules were seen. Their nuclei appeared irregular with amorphous appearance of their chromatin (Figure 17). Some acini

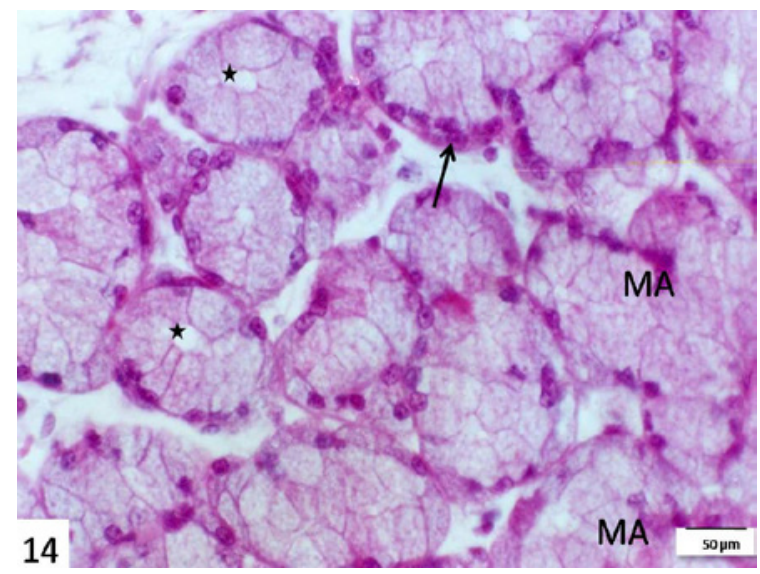

Figure 14: A section in the submandibular gland of 14 days starved group stained with H\&E showing distortion of mucous acini (MA), some of them with dilated lumens (star) and atrophied serous demilunes (arrow). Scale bar=50 $\mu \mathrm{m}$

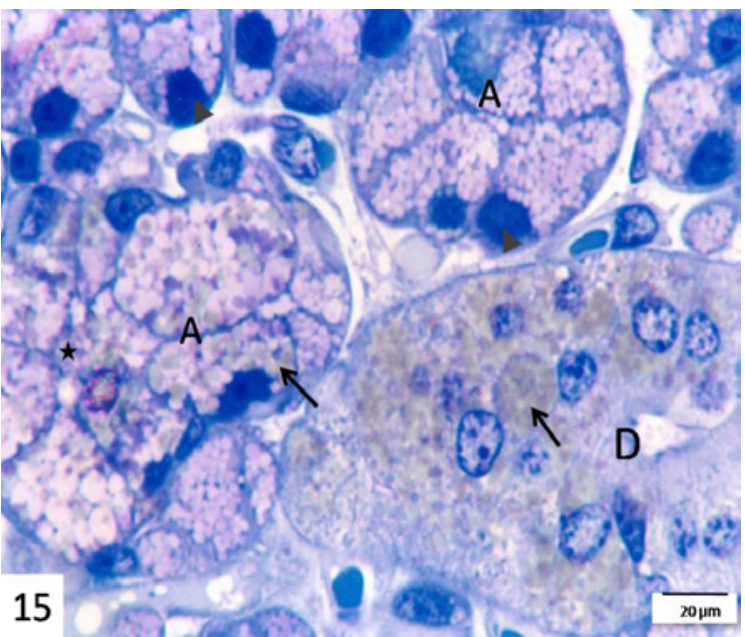

Figure 15: A semithin section in the submandibular gland of 14 days starved group stained with toluidine blue showing irregular shaped small sized acini (A) with dark irregular nuclei (arrow heads) and lossed of both metachromatic and orthochromatic secretory material. Note, the graying lipid droplets (arrows) in acinar cells and in the cells of striated duct (D). Note, few deeply stained blue granules near the luminal surface of the acinar cells (star). Scale bar=20 $\mu \mathrm{m}$. 
Citation: EL-Kordy EA, Alanazi AD, Ali SS, Makhlouf MMM, Rabah SO (2014) Histological, Histochemical and Ultrastructural Changes in the Submandibular Gland of Starved Young Male Cats. J Cytol Histol 5: 252. doi:10.4172/2157-7099.1000252

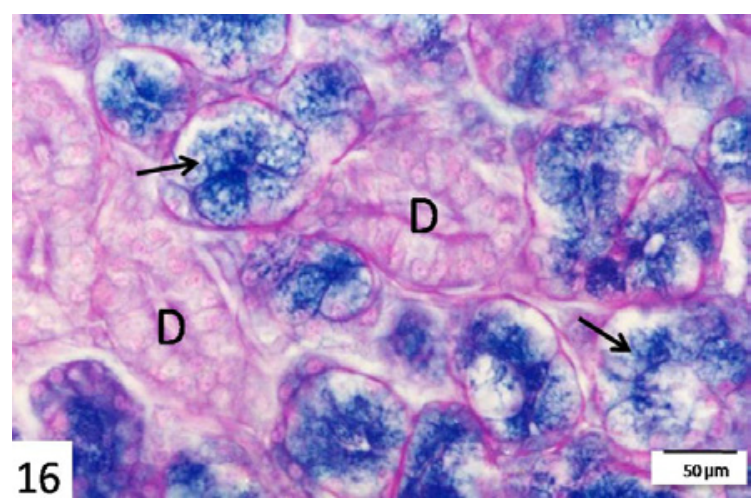

Figure 16: A section in the submandibular gland of 14 days starved group stained with Alcian blue-PAS stain showing marked decrease in the staining intensity of the secretory granules (arrows). The striated ducts (D) showed slight increase in the intensity of both stains in its cells. Scale bar $=50 \mu \mathrm{m}$.

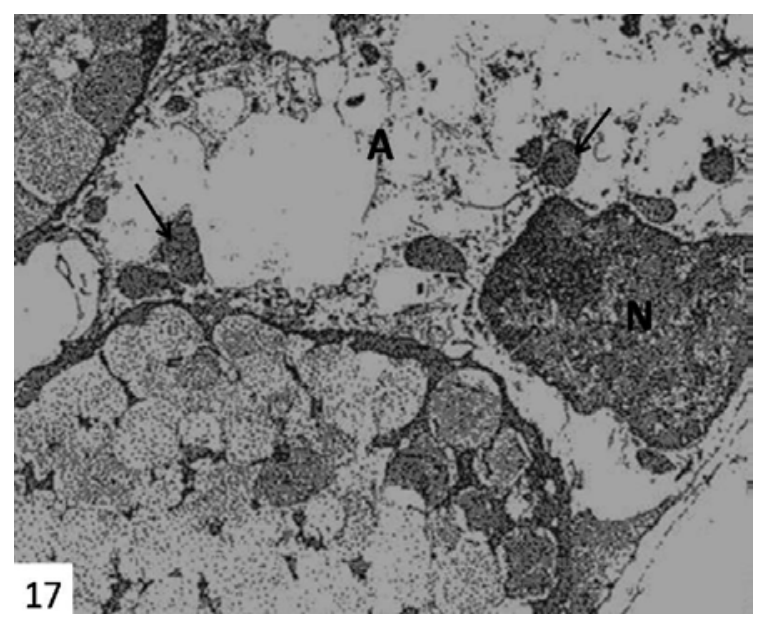

Figure 17: An electron micrograph of submandibular gland of 14 days starved group showing sever degenerated degranulated acinar cell (A) with complete loss of all cytoplasmic organelles and irregular nucleus with amorphous appearance of its chromatin (N). Note, numerous small electron dense deposits (arrows) in the cytoplasm. $\times 4000$.



Figure 18: An electron micrograph of submandibular gland of 14 days starved group showing marked accumulation of lipid droplets $(L)$ in the acinar cells, few scattered secretory granules (arrow) and filamentous residue represent remnants of disrupted granules (dotted arrow). Note, a part of irregular pyknotic nucleus $(\mathrm{N})$. X4000. showed marked disruption of the membrane bounded secretory granules accompanied by loss of their secretory content leaving only filamentous residue. Numerous lipid droplets were observed randomly distributed among the altered secretory granules. The nuclei appeared shrunken, irregular with condensed chromatin (Figures 18 and 19). The striated duct cells showed progressive destruction of the basal infoldings and fragmentation of mitochondrial cristae. The cytoplasm appeared rarified with fragmented filaments and granules. Also, significant accumulations of large lipid droplets were observed in duct cells. The nuclei appeared small and irregular with dense chromatin (Figure 20).

\section{Discussion}

Starvation essentially means starving the body of vital nutrients it needs to function and survive. Starvation can be caused from outside sources beyond someone's control or it can be entirely self-inflicted. In laboratory studies, starvation has been associated with numerous deleterious changes in the physiology of various organs and body systems suggesting potential for subsequent health problems [19].

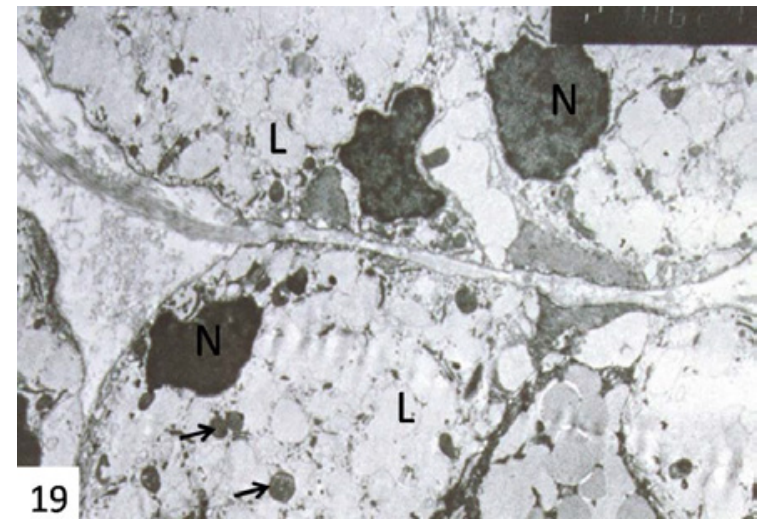

Figure 19: An electron micrograph of submandibular gland of 14 days starved group showing multiple acinar cells with pyknotic nuclei $(\mathrm{N})$ and marked accumulation of lipid droplets (L). Note, few scattered secretory granules (arrows). X 2700.

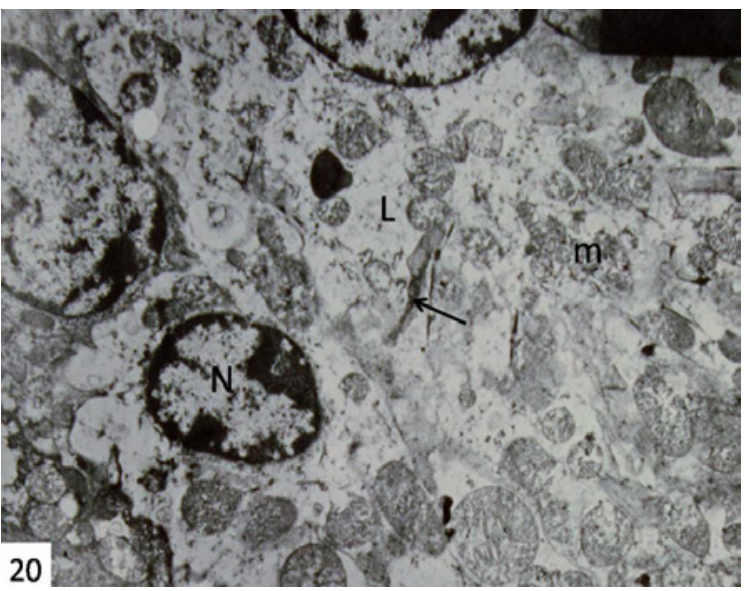

Figure 20: An electron micrograph of submandibular gland of 14 days starved group showing a striated duct cells with destructed mitochondria $(\mathrm{m})$, multiple lipid droplets $(L)$ in rarified cytoplasm, remnant of basal membrane infoldings (arrow) and small electron dense nucleus (N). X 4000. 
Laboratory animals have been very useful in studying the effects of varying levels of malnutrition because non-nutritional factors that affect humans may be controlled [20]. The behavior of salivary glands is very sensitive to the general condition of the body and to a variety of systemic diseases. Nevertheless, their functions and salivary flow rate as well as its composition are dependent upon food intake [21,22].

In the present study, long-term (7 and 14 days) food deprivation induced obvious histological, histochemical and ultrastructural changes in the cat submandibular gland. By light microscope, starvation for 7 days (subgroup IIa) produced remarkable changes in the parenchyma of submandibular gland of cat and these changes were augmented with prolongation of periods of starvation for 14 days (subgroup IIb). The changes were mostly observed in both acinar and demilune cells as well as in the striated ducts. The secretory units appeared distended with secretory granules, that make the cytoplasm look more vacuolated and less stainable compared to control. The nuclei appeared small, irregular and deeply stained being compressed by accumulated secretion.

Previous studies have reported histological alterations in salivary glands from rats fed a liquid diet, with a reduction in size of acinar and duct cells [23-25]. They attributed that to acinar cell shrinkage rather than to losses of acinar cell numbers. The loss of secretory cell mass may result in submandibular hypofunction and consequently the rate and volume of the salivary gland secretion were decreased. On the other hand, other investigators [26] found that liquid diet in rats does not induce atrophic alterations to acinar cells, including apoptosis and proliferative activity in submandibular and sublingual glands.

The histological results of the starved group (group II) were found to be parallel with histochemical observations of same group as starvation lead to decrease or alteration in metachromatic staining of secretory granules, where in other regions there was a complete loss of metachromasia. The contents of secretory units appeared orthochromatic indicating more neutral mucosubstances. Alcian bluePAS technique revealed also alteration in the histochemistry of secretory granules. The acinar cells exhibited a decrease in both acid and neutral mucosubstances while there is an increase in acid mucosubstances in demilune cells. With prolongation of the period of starvation for 14 day, the secretory granules of both acinar and demilune cells tend to be unstained by any of histochemical techniques as well as in semithin sections, the acinar cells appeared with few orthochromatic granules near their luminal surface or scattered randomely in the cytoplasm. By Alcian blue PAS technique, only fragmented reticulated Alcian blue positive substance was left inside the degenerating distorted acinar cells.

Literature is rich in information which all agreed that the volume, state and composition of saliva depend on the type of food and state of stimulation [27-29]. The $\mathrm{pH}$ of saliva is sensitive to the rate of flow as in sleep and fasting condition; it falls presumably to lower levels [30]. This report could explain what was observed in the present work that starvation for 7 days increase demilune cells acid mucopolysaccharides and only acid mucosubstances were observed in acinar cells at 14 days of starvation. The alteration in the histochemistry of secretory granules could be attributed to the accumulation of granules within the cells after failing to discharge due to lack of stimulation.

Fasting caused a significant decrease in secretion rate, concentration of phosphate and sialic acid in stimulated whole saliva. The decrease of the ratio of sialic acid to protein indicates a disturbance of glycoproteins biosynthesis. This effect might be caused by a general change in metabolism where the cell gives priority to pathways favoring the energy exchange instead of the complicated pathways necessary for glycosylation of proteins [31].

On the other hand these histochemical observations confirmed or explained the ultrastructural alteration of secretory contents observed in the present study as the acinar cells became engorged with altered secretory granules, the electron lucent appearance of normal granules was lost and the granules appear more electrons dense.

It was also observed that the accumulation of secretory granules is associated with pronounced degeneration of other cell organelles like rER and mitochondria and eventual cell death occurred. The decrease in cytoplasmic basophilia observed in the histological results of starved group (group II) may be correlated with the degeneration of the rER detected by the ultrastructural result of the same group. Similar observations were obtained by other study in rat submandibular gland exposed to fasting for 48 hours [32].

Other investigators had shown that he synthetic activity of submandibular gland to produce protein is reduced in corn fed rats for 2 months [33]. Also, severe degeneration in the form of enlarged granular endoplasmic reticulum, swollen mitochondria with reduction of secretory granules were found in the acinar and ductal cells of rat submandibular gland kept on liquid diet for 10 days [34].

Furthermre, mucosal atrophy of the adult rat intestine was reported after short period of starvation [13]. They reported that, during starvation, enzyme which neutralizes reactive oxygen species would be diminished, therefore the enterocyte would be more prone to inflammation and further damage [35].

In the present study, crystalloid formation and lysosomal appearance were not observed in cat submandibular gland and this may be explained by the solubility nature of mucopolysaccharides that in degeneration diffuse out of cells without need to lysosomal action.

The ultrastructure of the demilune cells showed marked alteration and degeneration of cellular organelles. The secretory granules were degenerating merging together due to disruption of their limiting membranes; they look unstained in semithin sections and electron lucent in electron micrographs.

The significant accumulation of lipid droplets within some acinar and demilune cells is of significant interest. Several alteration in lipid metabolism are known to accompany liquid diet feeding [25], diabetes mellitus [36,37], aging process and severe senility $[38,39]$. The accumulation of lipid droplets in the acinar cells probably results from continued uptake of free fatty acids from plasma, coupled with a decrease in the cellular activity and inability of animals to convert them into glycogen. On the other hand, the degradation of intracellular membranous organelles could have a role in such lipid accumulation.

In accordance with our study, other investigators [32] observed accumulation of lipid droplets in the cytoplasm of acinar cells of submandibular and sublingual glands of diabetic rats following sate of fasting for 48 hours. They reported that insulin controls the lipid cycle in the gland via modifying the formation of insulin receptor complex.

The striated ducts were affected by starvation. There was loss of the basal infoldings together with degenerative changes in the cristae of mitochondria and in the cytoplasmic contents. Accumulation of lipid droplets were observed after 7 days of starvation and it was more evident in ducts of 14 days starved animals. Striated ducts have a role in the modification of salivary secretion provided by secretory units [12]. They were reported to reabsorb electrolytes and organic materials from primary saliva. They can also synthesize and secrete glycoprotein 
Citation: EL-Kordy EA, Alanazi AD, Ali SS, Makhlouf MMM, Rabah SO (2014) Histological, Histochemical and Ultrastructural Changes in the Submandibular Gland of Starved Young Male Cats. J Cytol Histol 5: 252. doi:10.4172/2157-7099.1000252

into saliva [28]. The accumulation of lipid droplets within their cells could be also due to decrease cellular activity and increase in the fatty acid uptake from plasma which was known to be increased during starvation.

The degenerative changes of submandibular gland observed in the present study may be attributed to loss of masticatory reflex stimulation and a decrease in all its functions during starvation. This is supported by previous study [25] who stated that the cause of acinar atrophy of the submandibular gland of the mice received a liquid diet for 21 days is linked to loss of masticatory reflex stimulation since this gland is situated and surrounded by muscular coats which included and assisted in the process of mastication and tongue movement [40].

On the other hand, secretory activity of salivary glands, like other exocrine glands of the digestive tract is under the control of both nerves and hormones $[40,41]$. Nutritional disturbances such as gross starvation is accompanied by complex morphological changes in neuroendocrine functions, so it has influence on salivary gland morphology as well as flow rate and composition in human and animals [42].

\section{Conclusion}

In conclusion, it was clear that food deprivation for long periods would markedly alter submandibular gland structure and saliva composition with a concomitant decrease in acid and neutral mucosubstances needed to lubricate oral and provide natural protection against dryness and infection.

\section{References}

1. Beltzer EK, Fortunato CK, Guaderrama MM, Peckins MK, Garramone BM, et al. (2010) Salivary flow and alpha-amylase: collection technique, duration, and oral fluid type. Physiol Behav 101: 289-296.

2. Ono K, Morimoto $Y$, Inoue H, Masuda W, Tanaka T, et al. (2006) Relationship of the unstimulated whole saliva flow rate and salivary gland size estimated by magnetic resonance image in healthy young humans. Arch Oral Biol 51: 345-349.

3. Mescher AL (2010) Junqueira's basic histology. text and atlas. (12 ${ }^{\text {th }}$ edn) New York: Lange.

4. Bradley PJ, Guntinas-Lichius O (2011) Salivary Gland Disorders and Diseases: Diagnosis and Management. Thieme, Stuttgart, New York.

5. Amano O, Mizobe K, Bando Y, Sakiyama K (2012) Anatomy and histology of rodent and human major salivary glands: -overview of the Japan salivary gland society-sponsored workshop-. Acta Histochem Cytochem 45: 241-250.

6. Adnyane IK, Zuki AB, Noordin MM, Agungpriyono S (2010) Histological study of the parotid and mandibular glands of barking deer (Muntiacus muntjak) with special reference to the distribution of carbohydrate content. Anat Histol Embryol 39: 516-520.

7. Dodds MW, Johnson DA, Yeh CK (2005) Health benefits of saliva: a review. J Dent 33: 223-233.

8. Schipper RG, Silletti E, Vingerhoeds MH (2007) Saliva as research material: biochemical, physicochemical and practical aspects. Arch Oral Biol 52: 11141135.

9. Sreebny LM, Vissink A (2010) Dry mouth, the malevolent symptom: a clinical guide. Singapore: Wiley-Blackwell.

10. de Almeida Pdel V, Grégio AM, Machado MA, de Lima AA, Azevedo LR (2008) Saliva composition and functions: a comprehensive review. J Contemp Dent Pract 9: 72-80.

11. Mravak-Stipetic M (2012) Xerostomia - diagnosis and treatment. Medical Sciences 38: 69-91.

12. Fawcett Don W, Jensh R P (2002) Bloom and Fawcett concise histology a text book of histology. LTP Arnald London, New York, Delhi.

13. Maulidyan A, Kusmayadi DD, Hernowo BS, Murni TW (2013) The effects of probiotics during refeeding period on jejunum mucosal morphology after shortterm starvation in Wistar rats. Crit Care \& Shock 16: 83-89.
14. Harvey RA, Ferrier DR (2011) Lippincott's Illustrated Reviews: Biochemistry Chapter VIII. Liver in fasting. Lippincott Williams \& Wilkins.

15. Calle E, Linden VA, Desfeux JG, Veening HP (2006) Barendregt and EW. Roubos: Effect of starvation on Fos and neuropeptide immunoreactivities in the brain and pituitary gland of Xenopus laevis. General and Comparative Endocrinology. 147: 237-246.

16. Turner RJ1, Sugiya $H$ (2002) Understanding salivary fluid and protein secretion Oral Dis 8: 3-11.

17. Kienran JA (2008) Histological and histochemical methods: Theory and practice. ( $4^{\text {th }}$ edn), Bloxham, UK: Scion Publishing.

18. Ayache J, Beaunier L, Boumendil J, Ehret G, Laub D (2010) Sample Preparation Handbook for Transmission Electron Microscopy Techniques. Springer, New York, Dordrecht Heidelberg, London.

19. Julie Boehlke (2011) The side effects of starvation. www.livestrong.com. Food and Drink. Last updated: Mar 21, 2011.

20. Cortés-Barberena E, González-Márquez H, Gómez-Olivares JL, Ortiz-Muñiz $R(2008)$ Effects of moderate and severe malnutrition in rats on splenic $T$ lymphocyte subsets and activation assessed by flow cytometry. Clin Exp Immunol 152: 585-592.

21. Tasukinok K, Saruta J, Selichi $Y$ and Masatu T (2011) The salivary gland and systemic health: Towards the creation of salivary gland and health medicine. $J$ of Oral Biosciences. 53: 330-37.

22. Sahin I, Aydin S, Ozkan Y, Dagli AF, Akin KO, et al. (2011) Diet-induced obesity suppresses ghrelin in rat gastrointestinal tract and serum. Mol Cell Biochem 355: 299-308.

23. Leal SC, Toledo OA, Bezerra AC (2003) Morphological alterations of the parotid gland of rats maintained on a liquid diet. Braz Dent J 14: 172-176.

24. Al Okaili AG, Sedeeq BI, Khudeer JM (2009) Histological changes of the parotid gland of mice maintained on a liquid diet. Tikrit Journal of Pure Science. 14: 64-67.

25. Al Okaili AG, Sedeeq BI and Hazeem MI (2009) Histological changes of the submandibular salivary gland of mice maintained on a liquid diet. Tikrit Journal of Pure Science. 14: 22-25

26. Takahashi S1, Uekita H, Kato T2, Yuge F2, Ushijima N2, et al. (2014) Immunohistochemical and ultrastructural investigation of acinar cells in submandibular and sublingual glands of rats fed a liquid diet. Tissue Cell 46 : 136-143.

27. Edgar M, Dawes C and O'Mullane D (2004) Saliva and oral health. ( $3^{\text {rd }}$ edn) London: BDJ Books.

28. Ekström J, Khosravani N, Castagnola M, Messana I (2012) Dysphagia, Medica Radiology. Springer-Verlag Berlin Heiderberg.

29. Elishoov H, Wolff A, Kravel LS, Shiperman A, Gorsky M (2008) Association between season and temperature and unstimulated parotid and submandibular/ sublingual secretion rates. Arch Oral Biol 53: 75-78.

30. Psoter WJ, Spielman AL, Gebrian B, St Jean R, Katz RV (2008) Effect of childhood malnutrition on salivary flow and pH. Arch Oral Biol 53: 231-237.

31. Johansson I, Ericson T, Steen L (1984) Studies of the effect of diet on saliva secretion and caries development: the effect of fasting on saliva composition of female subjects. J Nutr 114: 2010-2020

32. Take G, Ilgaz C, Erdogan D, Ozogul C, Elmas C (2007) A comparative study of the ultrastructure of submandibular, parotid and exocrine pancreas in diabetes and fasting. Saudi Med J 28: 28-35.

33. El-Nozahy AA, Ismail MI2 (2013) The response of rat submandibular salivary gland to plant protein diet; Biological and histochemical study. Int J Health Sc (Qassim) 7: 309-315.

34. Kuntsal L, Firat D, Sirin Y (2003) Prevention of liquid-diet-induced damages on submandibular glands by selenium supplementation in rats. Tohoku $\mathrm{J}$ Exp Med 201: 191-199.

35. Swiderska-Kolacz G, Klusek J, Kolataj A, Faray J (2006) Effect of starvation and immobilization on glutathione level and activity of glutathione enzymes in the liver and kidney of rabbits. Slov J Anim Sci. 39: 151-154.

36. Liu W, Hao J, Zhu L, Li F, Liu Q, et al. (2013) Phospho-GSK-3î́2 is involved in the high-glucose-mediated lipid deposition in renal tubular cells in diabetes. Int J Biochem Cell Biol 45: 2066-2075. 
Citation: EL-Kordy EA, Alanazi AD, Ali SS, Makhlouf MMM, Rabah SO (2014) Histological, Histochemical and Ultrastructural Changes in the Submandibular Gland of Starved Young Male Cats. J Cytol Histol 5: 252. doi:10.4172/2157-7099.1000252

Page 9 of 9

37. Mahay S, Adeghate E, Lindley MZ, Rolph CE, Singh J (2004) Streptozotocininduced type 1 diabetes mellitus alters the morphology, secretory function and acyl lipid contents in the isolated rat parotid salivary gland. Mol Cell Biochem 261: 175-181.

38. Azevedo LR, Damante JH, Lara VS, Lauris JR (2005) Age-related changes in human sublingual glands: a post mortem study. Arch Oral Biol 50: 565-574.

39. Singh K, Kaur S, Kumari K, Singh G, Kaur A (2009) Alterations in lipid peroxidation and certain antioxidant enzymes in different age groups under physiological conditions. J Hum Ecol 27: 143-147.
40. Proctor GB, Carpenter GH (2007) Regulation of salivary gland function by autonomic nerves. Auton Neurosci 133: 3-18.

41. Cevik-Aras H, Godoy T, Ekstrom J (2011) Melatonin-induced protein synthesis in the rat parotid gland. J Physiol Pharmacol 62: 95-99.

42. Ishikawa $Y$, Chen $C$, Ishida $H$ (1993) The effect of starvation on the diurna variation of amylase secretion from rat parotid glands. Res Exp Med (Berl) 193: $255-262$. 